\title{
The spring transition of the North Pacific jet and its relation to deep stratosphere-to-troposphere mass transport over western North America
}

\author{
Melissa L. Breeden ${ }^{1}$, Amy H. Butler ${ }^{1}$, John R. Albers ${ }^{2,4}$, Michael Sprenger ${ }^{3}$, and Andrew O'Neil Langford ${ }^{1}$ \\ ${ }^{1}$ NOAA Chemical Sciences Laboratory, Boulder, CO 80305, USA \\ ${ }^{2}$ NOAA Physical Sciences Laboratory, Boulder, CO 80305, USA \\ ${ }^{3}$ Institute for Atmosphere and Climate Science, ETH Zürich, Zurich, Switzerland \\ ${ }^{4}$ Cooperative Institute for Research in the Environmental Sciences, University of Colorado Boulder, Boulder, CO 80305, USA
}

Correspondence: Melissa L. Breeden (melissa.breeden@noaa.gov)

Received: 16 June 2020 - Discussion started: 25 September 2020

Revised: 10 December 2020 - Accepted: 18 December 2020 - Published: 24 February 2021

\begin{abstract}
Stratosphere-to-troposphere mass transport to the planetary boundary layer (STT-PBL) peaks over the western United States during boreal spring, when deep stratospheric intrusions are most frequent. The tropopause-level jet structure modulates the frequency and character of intrusions, although the precise relationship between STT-PBL and jet variability has not been extensively investigated. In this study, we demonstrate how the North Pacific jet transition from winter to summer leads to the observed peak in STT-PBL. We show that the transition enhances STTPBL through an increase in storm track activity which produces highly amplified Rossby waves and more frequent deep stratospheric intrusions over western North America. This dynamic transition coincides with the gradually deepening PBL, further facilitating STT-PBL in spring. We find that La Niña conditions in late winter are associated with an earlier jet transition and enhanced STT-PBL due to deeper and more frequent tropopause folds. An opposite response is found during El Niño conditions. El Niño-Southern Oscillation (ENSO) conditions also influence STT-PBL in late spring or early summer, during which time La Niña conditions are associated with larger and more frequent tropopause folds than both El Niño and ENSO-neutral conditions. These results suggest that knowledge of ENSO state and the North Pacific jet structure in late winter could be leveraged for predicting the strength of STT-PBL in the following months.
\end{abstract}

\section{Introduction}

The annual cycle of the North Pacific jet drives changes in the circulation response to external perturbations, thereby modifying sensible weather over North America (Fleming et al., 1987; Nakamura, 1992; Newman and Sardeshmukh, 1998; Lareau and Horel, 2012). The jet is strongest during boreal winter due to the overlapping of a polar jet forming via lowlevel baroclinicity and a subtropical jet forming via outflow from tropical convection (Eichelberger and Hartmann, 2007; Jaffe et al., 2011; Li and Wettstein, 2012; Christenson et al., 2017). The jet weakens during spring to its summertime minimum as both baroclinicity and tropical convection weaken. This study will focus on how the wintertime jet evolves during spring, which we will refer to as the spring transition. Newman and Sardeshmukh (1998) found that the North Pacific jet transitions from one contiguous jet core to a doublejet structure in mid-March, including a subtropical branch that extends southeastward from a point near the date line to the southern United States and a midlatitude branch in the west and central Pacific. This transition coincides with a peak in storm track activity (Nakamura, 1992; Hoskins and Hodges, 2019) as the background zonal wind and stationary eddy characteristics are strongly linked (Nakamura, 1992; Hoskins and Ambrizzi, 1993).

How the spring transition affects stratospheric intrusions associated with both potent cyclogenesis and, the focus of this study, stratosphere-to-troposphere mass transport to the planetary boundary layer (STT-PBL) has not been exten- 
sively investigated. Škerlak et al. (2014) highlighted a climatological maximum in STT-PBL during boreal spring over western North America, which they attributed, in part, to a deep arid boundary layer while noting a substantial amount of forcing for descent must also be present. The timing in the peak of deep transport differs from peak transport across the tropopause, which is strongest in boreal winter (Sprenger and Wernli, 2003; Škerlak et al., 2014), highlighting the unique nature of deep transport events. Given the peak in North Pacific storm track activity during boreal spring and corresponding peak in STT-PBL, we hypothesize that the invigoration of the storm track from late winter to spring produces stronger stratospheric intrusions, enhancing STT-PBL.

Natural, non-local sources of ozone to the surface need to be understood and accounted for when creating exceedance limits above the background level for the National Ambient Air Quality Standard (NAAQS). Consistent with the typical seasonal evolution of STT-PBL presented by Škerlak et al., 2014, cases of deep stratospheric-ozone intrusions over the western United States have focused predominantly on boreal spring, when intrusions can contribute substantially to the tropospheric ozone budget (Staley, 1962; Langford et al., 2009, 2012, 2017; Lefohn et al., 2012; Lin et al., 2012, 2015; Knowland et al., 2017; Škerlak et al., 2019). Deep intrusions are commonly observed on the southwest edge of cyclonic potential vorticity (PV) anomalies associated with deep midtropospheric troughs, where air is descending along isentropic surfaces, transporting filaments of PV- and ozone-rich stratospheric air into the troposphere (Reed and Danielsen, 1959; Danielsen, 1964, 1968; Shapiro, 1980; Keyser and Shapiro, 1986; Sprenger et al., 2007; Gettelman et al., 2011). From these case studies, it is evident that several synoptic situations, with the common element of highly amplified flow and often Rossby wave breaking, can facilitate STTPBL (e.g., Sprenger et al., 2007). However, there is a clear peak in transport during boreal spring, suggesting a unique set of conditions exist during the spring transition that are conducive to deep transport.

Some studies have noted spring seasons with exceptionally elevated STT-PBL (Lin et al., 2015; Knowland et al., 2017) while some are characterized by relatively minimal STT-PBL (Lin et al., 2015). We will demonstrate that this interannual variability of STT-PBL during spring is related to the timing of the spring transition and, often, the state of the El Niño-Southern Oscillation (ENSO). ENSO phase can influence the state of the North Pacific jet (Renwick and Wallace, 1996; Shapiro et al., 2001; Martius et al., 2007; Breeden et al., 2020) and STT, although cross-tropopause transport and deep transport display inconsistent responses to ENSO phase (Langford et al., 1998; Zeng and Pyle, 2005; Voulgarakis et al., 2011; Lin et al., 2014, 2015; Neu et al., 2014; Albers et al., 2018). In the mid-troposphere, El Niño conditions can enhance STT in much of the free troposphere through shallow folding along the stronger, extended jet. Conversely, La Niña conditions have been associated with enhanced strato- spheric contributions to surface ozone at several monitoring stations located in the western United States, suggesting there is stronger STT-PBL during La Niña conditions compared to El Niño (Lin et al., 2015).

While preliminary results suggest a relationship between ENSO, North Pacific jet variability and STT-PBL over the western US, further investigation of the linkages between these factors is warranted. For instance, changes in specific characteristics of tropopause folds by ENSO phase - such as their vertical and lateral extent and their frequency - have not been considered, nor have these changes been explicitly linked to variations in STT-PBL. It is the objective of this study to address these sources of STT-PBL variability using feature-based products designed to study deep transport (Sprenger et al., 2017). We focus on how ENSO modifies the seasonal transition of the North Pacific jet, thereby affecting the timing, frequency, and characteristics of stratospheric intrusions and STT-PBL. Section 2 presents the data and methods used for analysis, Sect. 3.1 presents characteristics of the North Pacific jet transition, Sect. 3.2 relates the transition to STT-PBL, and Sect. 3.3 explores the influence of ENSO on the seasonal transition and STT-PBL. Section 4 offers a discussion of results and concluding remarks.

\section{Data and methods}

\subsection{Data}

Zonal and meridional wind on pressure levels was accessed from the Japanese Reanalysis-55 dataset (Kobayashi et al., 2015 ), at $2.5 \times 2.5^{\circ}$ horizontal resolution at $6 \mathrm{~h}$ time intervals, from February-June 1958-2017, and the European Centre for Medium-Range Forecasting (ECMWF) ERA-Interim dataset (Dee et al., 2011) at $1 \times 1^{\circ}$ horizontal resolution at $6 \mathrm{~h}$ time intervals from February-June 1979-2017. The lower horizontal resolution of JRA-55 was used due to our interest in large-scale patterns of variability, and the resolution difference does not influence the resultant analysis. The 60year JRA-55 reanalysis is used to compare the spring transition for as many ENSO events as possible (Fig. 8), while ERA-Interim is used to be consistent with the transport and tropopause fold diagnostics that were derived from ERAInterim reanalysis. Both datasets use four-dimensional variational data assimilation schemes, and for JRA-55 there is good consistency between the pre- and post-satellite era values (Kobayashi et al., 2015). The fold and transport diagnostics, described below, were determined using ERA-Interim on the original 60 hybrid model levels, deemed suitably high vertical resolution for tracking these small-scale features (Škerlak et al., 2014, 2015). The state of ENSO was evaluated using the monthly Oceanic Niño Index (ONI) which is based on a threshold of $\pm 0.5^{\circ} \mathrm{C}$ (positive indicating $\mathrm{El}$ Niño, negative indicating La Niña) averaged over the Niño 3.4 region $\left(5^{\circ} \mathrm{N}-5^{\circ} \mathrm{S}, 120-170^{\circ} \mathrm{W}\right.$; NOAA CPC). 
STT-PBL, calculated and presented in Škerlak et al. (2014), was accessed at $1 \times 1^{\circ}$ horizontal resolution and $6 \mathrm{~h}$ time intervals from February-June 1980-2016. STT-PBL is defined to occur when trajectories that originate in the stratosphere cross the tropopause and reach a pressure value greater than that of the PBL top. First, kinematic trajectories were determined every $24 \mathrm{~h}$ globally from 50 to $650 \mathrm{hPa}$ using the tool introduced in Wernli and Davies (1997). Stratospheric trajectories, determined using an advanced threedimensional labeling algorithm (Škerlak et al., 2014), that crossed the tropopause were then identified, and their maximum pressure value tracked as they evolved forward in time. If a trajectory's pressure value exceeded the pressure of the PBL top, then it was flagged and converted to an amount of mass: $\Delta m \approx \frac{1}{g}(\Delta x)^{2} \Delta p \approx 6.52 \times 10^{11} \mathrm{~kg}$, where $\Delta x=$ $80 \mathrm{~km}$ and $\Delta p=30 \mathrm{hPa}$, in the extratropics (Škerlak et al., 2014). PBL height was determined using the $6 \mathrm{~h}$ forecast by the ECMWF model. Using PBL height instead of a fixed pressure level to define deep STT improves identification of deep STT over mountainous regions, particularly important for this study.

For a measure of the depth of stratospheric intrusions that lead to STT-PBL over western North America, the tropopause fold identification scheme developed by Škerlak et al. (2015) was used at $6 \mathrm{~h}$ temporal resolution and $1 \times 1^{\circ}$ horizontal resolution. Building upon the fold identification scheme introduced by Sprenger and Wernli (2003), tropopause folds were identified by first distinguishing between air of stratospheric and tropospheric origin on a potential vorticity basis using a three-dimensional labeling scheme. Folds of stratospheric origin are then identified when there were multiple crossings of the tropopause (defined using surfaces of the \pm 2 PVU (potential vorticity unit, $1 \mathrm{PVU}=10^{-6} \mathrm{~K} \mathrm{~m}^{2} \mathrm{~kg}^{-1} \mathrm{~s}^{-1}$ ) surface and $380 \mathrm{~K}$ potential temperature, tropopause marked at whichever surface is lower), observed within a single vertical profile. At locations where folds were identified, the minimum and maximum pressure the fold reached was recorded (Fig. S1). To examine how the jet transition, and later ENSO phase, affects the depth of tropopause folds, we tracked the maximum pressure a fold, if identified over the western US (box in Fig. S1), reached for each $6 \mathrm{~h}$ time step. The size of folds deeper than $400 \mathrm{hPa}$ was also tracked by counting the number of grid points over the region that were characterized by a maximum pressure greater than $400 \mathrm{hPa}$. The number of grid points meeting this criterion was then divided by the number of grid points over the western US domain. The number of time steps characterized by a fold with a maximum pressure greater than $400 \mathrm{hPa}$ was also recorded, for a measure of the frequency of tropopause folds under various large-scale conditions. Any mention of tropopause fold frequency therefore refers to only this subset of folds, as folds shallower than $400 \mathrm{hPa}$ are unlikely to affect STT-PBL. Similar results are found when folds larger or deeper than $500 \mathrm{hPa}$ are selected, although differences in the size of intrusions are more difficult to discern given the small-scale nature of intrusions this deep (e.g., Knowland et al., 2017).

We note that the 2-PVU surface, which is used to define the maximum pressure folds reached and marks the "dynamic tropopause" boundary (Hoskins et al., 1985), does not always mark the terminus of the fold, and that ozone originating in the stratosphere more closely follows the 1PVU surface which penetrates further downward, as shown in Albers et al. (2018; their Fig. 2). Shapiro (1980) also discussed how ozone associated with a tropopause fold in March 1978 reached farther into the troposphere than the dynamic tropopause, indicative of cross-isentropic mixing. Knowland et al. (2017) examined cross sections of two stratospheric intrusions that led to enhanced surface ozone concentrations in Colorado in spring 2012 and showed that the dynamic tropopause only reached to the mid-troposphere, with only small filaments of the intrusion reaching deeper than $500 \mathrm{hPa}$, while high stratospheric-ozone values extended to the surface. For these reasons, we believe that tracking when the dynamic tropopause is deeper than $400 \mathrm{hPa}$ captures the structures often associated with transport deep into the troposphere. This is confirmed by the strong relationship between STT-PBL and the fold characteristics discussed in Sect. 3.3. Changes in these measures of fold depth, size, and frequency will be evaluated during the phases of the spring transition, as well as during El Niño, La Niña, and ENSO-neutral conditions.

\subsection{Post-processing and diagnostics}

We use the leading empirical orthogonal function (EOF1) and principal component (PC1) time series of the daily mean $200 \mathrm{hPa}$ zonal wind over the North Pacific basin (100$280^{\circ} \mathrm{E}, 10-70^{\circ} \mathrm{N}$ ), smoothed with a $5 \mathrm{~d}$ running mean, to track the seasonal evolution of the jet. Zonal wind anomalies used for EOF analysis were calculated with respect to the February-June 1958-2017 average using JRA-55 reanalysis (black contours, Fig. 1a), with the resultant anomalies intentionally including changes associated with the seasonal cycle (in contrast to the more canonical approach, in which the seasonal cycle is removed). To be consistent with the STT-PBL and tropopause fold datasets, which are based upon ERAInterim reanalysis (Sprenger et al., 2017), we recomputed the $200 \mathrm{hPa}$ zonal wind EOFs in the same manner using ERAInterim $200 \mathrm{hPa}$ zonal wind (the correlation between PC1 using JRA55 and ERA-Interim for their common period, 19792017, is 0.99).

For a measure of the eddy characteristics and horizontal Rossby wave energy propagation during various phases of the spring transition, the horizontal $\boldsymbol{E}$ vector (Eq. 1; Hoskins et al., 1983) was calculated using daily zonal and meridional wind anomalies that have (a) the 60-year daily climatology and (b) the $11 \mathrm{~d}$ running mean removed. Regions where $\boldsymbol{E}$ points eastward (westward) are characterized by meridion- 


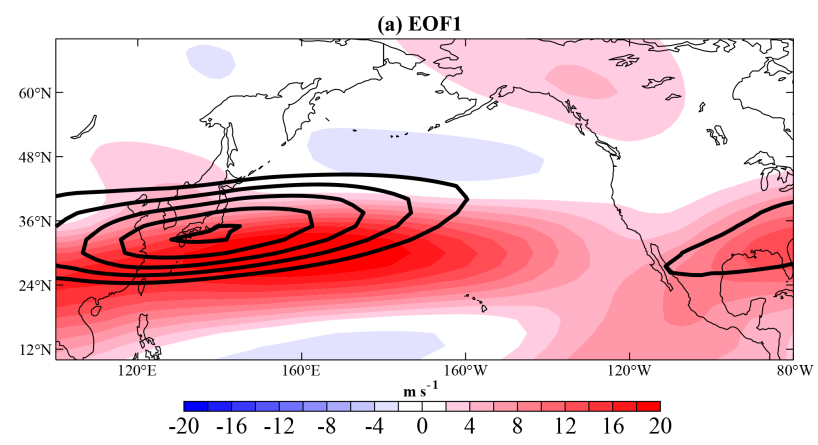

(b) PC1

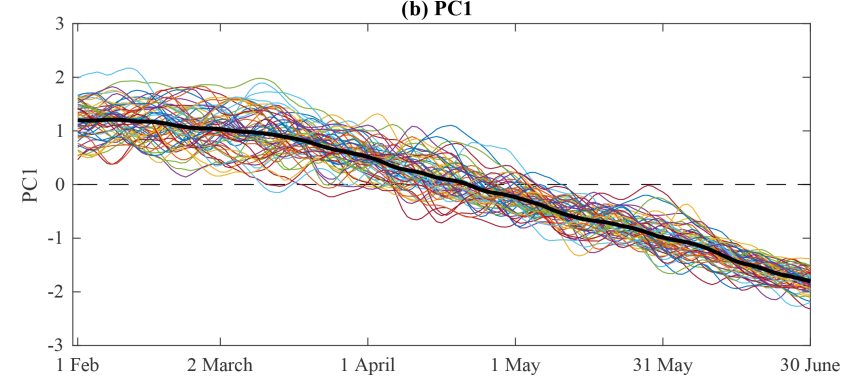

Figure 1. The color shading in (a) is the EOF1 zonal wind anomaly pattern associated with $\mathrm{a}+1 \sigma \mathrm{PC} 1$, and the black contours show the FMAMJ (February-June) 1958-2017 mean zonal wind, with contours starting at $30 \mathrm{~m} \mathrm{~s}^{-1}$ every $5 \mathrm{~m} \mathrm{~s}^{-1}$. The percent variance explained by EOF1 is $40 \%$ and is well separated from the next EOFs according to the criterion of North (North 1982). (b) The thin lines plot each year's PC1 evolution, and the thick black line shows the 60-year average.

ally (zonally) elongated eddies (Fig. S2). Negatively tilted anomalies, indicative of cyclonic wave breaking, correspond to a northward-pointed $\boldsymbol{E}$ and energy propagation, while positively tilted anomalies indicate anticyclonic wave breaking and correspond to southward-pointed $\boldsymbol{E}$ and energy propagation.

$\boldsymbol{E}=\left[\overline{v^{\prime 2}-u^{\prime 2}},-\overline{u^{\prime} v^{\prime}}\right]$

\subsection{Significance testing}

For a measure of confidence in the differences in fold characteristics and STT-PBL during different jet phases and ENSO conditions, mean values were bootstrapped using a sample size $N_{\text {eff }}=\mathrm{N} / \mathrm{t}_{\text {autocorr }}$, where $t_{\text {autocorr }}$ is the number of time steps at which the autocorrelation of the variables decreases to below 0.5 and $N$ represents the number of samples in the smallest group being compared. For example, when comparing STT-PBL over North America during May El Niño, La Niña, and ENSO-neutral conditions, with corresponding samples sizes $(N)$ equal to 20,9 , and 7 years, respectively, STT-PBL for the three groups is resampled using $N=7$ years $\times 124$ time steps/year $=868$ time steps and $t_{\text {autocorr }}=6$ time steps $(36 \mathrm{~h})$, which equates to $N_{\text {eff }}=144$ time steps. To fairly compare the confidence intervals for
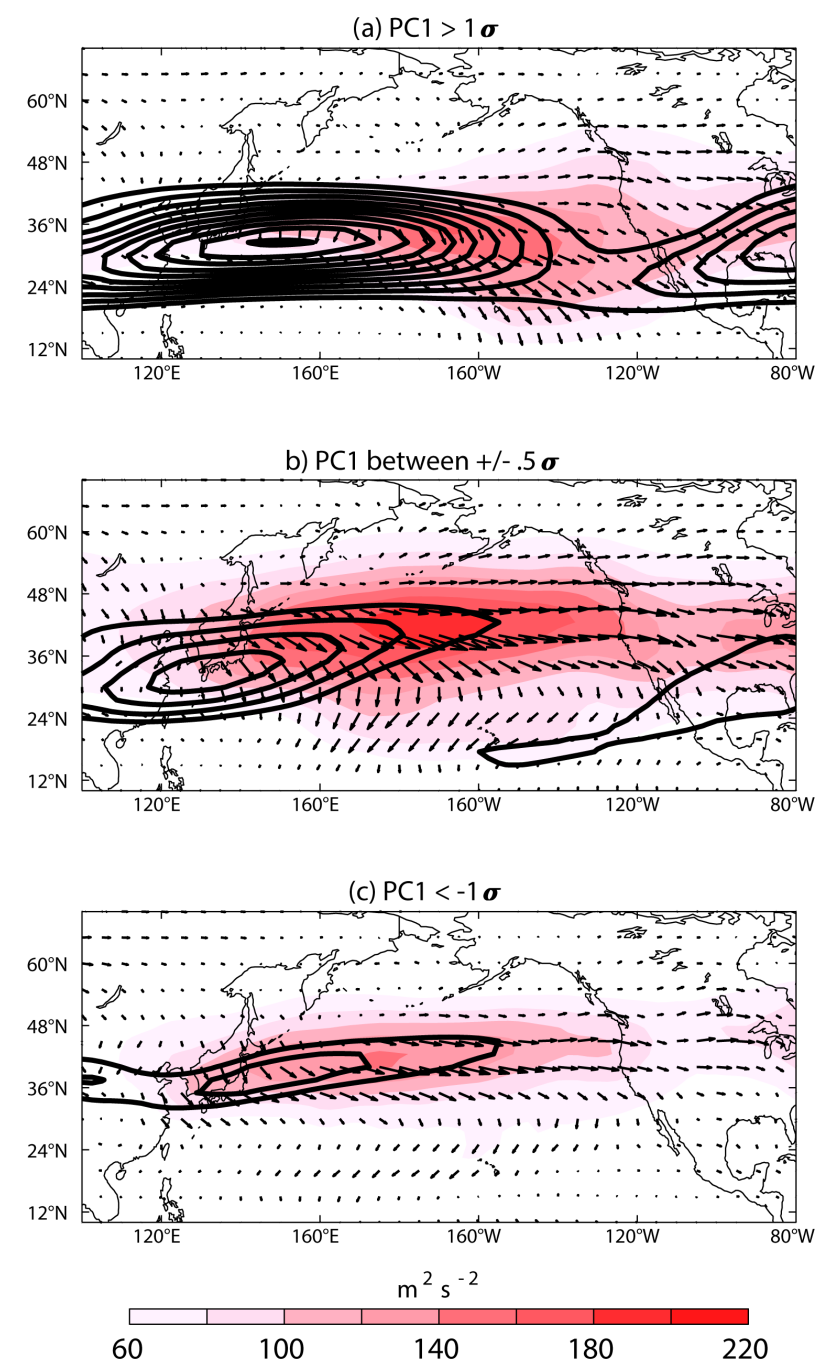

Figure 2. The black contours show the full-field $200 \mathrm{hPa}$ zonal wind composited for days characterized by (a) positive PC1 $(N=1720)$, (b) neutral PC1 $(N=1455)$, and (c) negative PC1 $(N=1855)$. Zonal wind contours start at $30 \mathrm{~m} \mathrm{~s}^{-1}$ at intervals of $5 \mathrm{~m} \mathrm{~s}^{-1}$. The color shading shows the composite high-frequency EKE during the positive, neutral, and negative jet phases, and the corresponding composite horizontal $\boldsymbol{E}$ vector is shown in the black arrows.

each ENSO group, every group was resampled using the reduced sample size $N_{\text {eff }}$ to calculate a new mean STT-PBL value. This process was repeated 10000 times to determine the 95th and 5th percentiles of the mean value for each group. A similar approach was applied to each variable considered.

\section{Results}

\subsection{Characteristics of the spring North Pacific jet transition}

The leading EOF pattern of $200 \mathrm{hPa}$ zonal wind tracks the seasonal evolution of the North Pacific jet from February 
through June each year (Fig. 1). A positive PC1 value represents the stronger wintertime state (Fig. 1a), which gradually weakens on average from about March through June, as shown by the transition of PC1 from positive to negative each year (Fig. 1b). There is greater spread among the PCs of individual years during February, March, and April than there is during May and June, indicating the transition from winter to spring is more variable than the transition from spring to summer. The composite zonal wind on days when PC1 $>1 \sigma$, hereafter referred to as the winter phase, most often occurring in February-March, is characterized by a strong jet extending well past the date line (Fig. 2a). During the winter phase, high-frequency eddy kinetic energy (EKE) is greatest in the jet exit region in the central Pacific, representing the wintertime Pacific storm track and tendency for eddies to amplify via deformation in the jet exit region (Rivière and Joly, 2006; Breeden and Martin, 2018). The prevalence of equatorward-pointed $\boldsymbol{E}$, signifying positively tilted waves, over North America is consistent with the frequency of positively tilted troughs and ridges identified during boreal winter by Schemm and Sprenger (2020).

As PC1 decreases to values between $\pm 5 \sigma$, which we define as the transition phase, the jet core weakens substantially, while the jet exit region shifts northward (Fig. 2b). The storm track is more energetic throughout the PacificNorth American region compared to the winter phase and shifts northward with the jet exit region. In the east Pacific, a distinct secondary jet maximum develops near Hawaii in the subtropics, creating a double-jet structure in the Pacific Basin which differs substantially from the strong, merged wintertime jet. The formation of this secondary zonal wind maximum was also observed to develop in April by Newman and Sardeshmukh (1998). The magnitude of $\boldsymbol{E}$ increases during the transition phase, with meridionally elongated, positively tilted waves dominating the structure in the midlatitude $\mathrm{Pa}$ cific. Such characteristics are related to frequent anticyclonic Rossby wave breaking associated with the formation of the two jet maxima (Peters and Waugh, 2003; Pan et al., 2009; Breeden and Martin, 2018) observed in the transition phase. A distinct region of nearly zonal $\boldsymbol{E}$ is observed over the eastern Pacific or western US, indicating waves in this region are more amplified meridionally compared to when the jet occupies the winter phase. Zonal wind, EKE, and eddy amplitude proceed to weaken by late spring or early summer, when PC1 $<-1 \sigma$, hereafter referred to as the summer phase (Fig. 2c), with the subtropical jet in the eastern Pacific essentially disappearing altogether. Over the western US, eddies are still meridionally amplified but less so than during the transition phase, characteristic of the weakened storm track.

To examine the variability in the spring transition, we tracked the date on which $\mathrm{PC} 1$ dropped below $+5 \sigma$ and remained below that value for the remainder of the season. We target this transition in particular given the high variability of PC1 early in the season and the marked invigoration of the storm track associated with PC1 decreasing from strongly
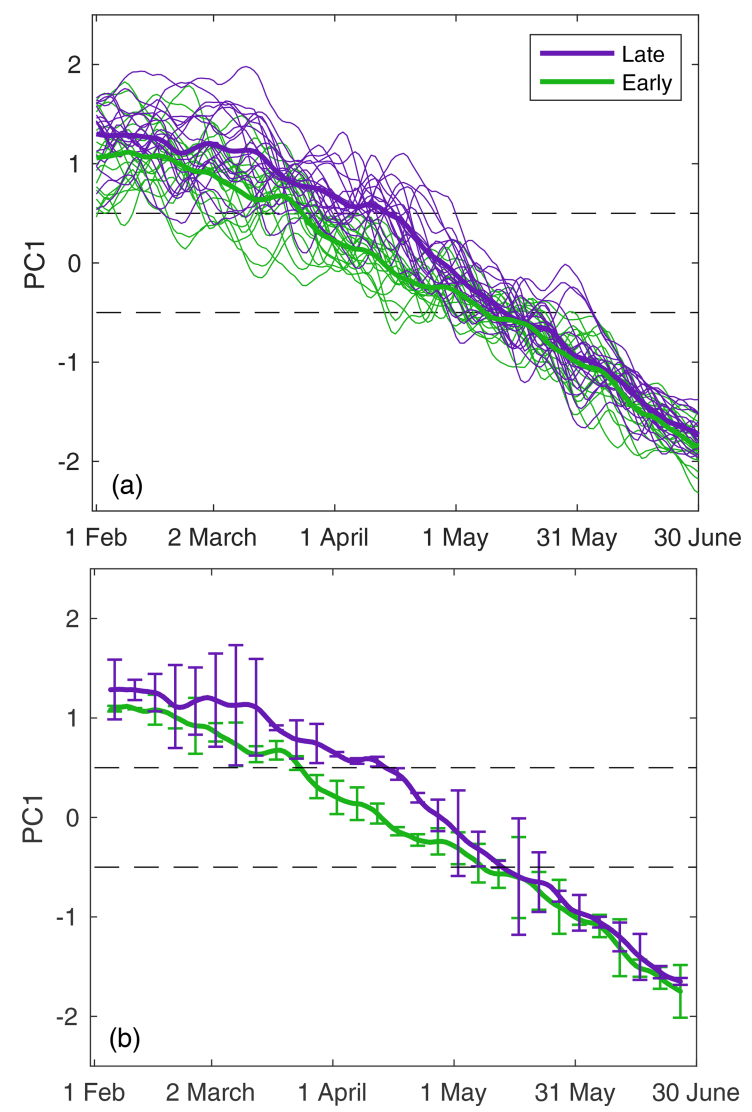

Figure 3. (a) The thick green and purple lines show the composite PC1 evolution and the thin green and purple lines show each year's PC1 evolution, during 18 early and 19 late transition years, respectively. Panel (b) shows confidence intervals for the composite PC1 values for the early (green) and late (purple) groups. The dashed lines show the $\pm 0.5 \sigma$ thresholds

positive to neutral. The mean transition date over the 60 year record is 4 April, with a standard deviation of $\pm 12 \mathrm{~d}$. To test if there are dynamic differences in the transition if it occurs earlier or later than normal, we grouped each spring into early, neutral, and late transition years, requiring early (late) transition years to have a transition date at least $5 \mathrm{~d}$ earlier (later) than the 60-year average (Table 1). The average timing of the transition for the three groups differs by about 2 weeks, with the early group transitioning on average in mid-March, the late group in mid-April. Comparing the composite February-June evolution of PC1 for the early and late groups (the neutral transition years fall in-between), PC1 in the early group begins to decrease near the beginning of March, although these differences are not significant until later in the month (Fig. 3). During April, the late group PC1 value is roughly $5 \sigma$ higher than the early group, with an average zonal wind difference of $10 \mathrm{~m} \mathrm{~s}^{-1}$ within the jet core, while by May the two groups are indistinguishable from one another. This indicates that an early winter-to-spring transition is not associated with an early spring-to-summer tran- 
Table 1. Years when the jet transitioned early, on time, or late, relative to the mean transition date of 3 April. Italic (bold) text denotes years when La Niña (El Niño) conditions were observed the month of the transition date.

\begin{tabular}{|c|c|c|}
\hline $\begin{array}{l}\text { Early transition years } \\
\text { mean transition date: } \\
21 \text { March }\end{array}$ & $\begin{array}{l}\text { On time transition years } \\
\text { mean transition date: } \\
3 \text { April } 3\end{array}$ & $\begin{array}{l}\text { Late transition years } \\
\text { mean transition date: } \\
17 \text { April }\end{array}$ \\
\hline 1960 (22 March) & 1958 (30 March) & 1966 (16 April) \\
\hline 1967 (25 March) & 1959 (30 March) & 1970 (13 April) \\
\hline 1968 (20 March) & 1961 (6 April) & 1975 (9 April) \\
\hline 1969 (28 March) & 1962 (3 April) & 1978 (15 April) \\
\hline 1971 (25 March) & 1963 (30 March) & 1983 (11 April) \\
\hline 1972 (23 March) & 1964 (2 April) & 1987 (14 April) \\
\hline 1976 (28 March) & 1965 (4 April) & 1990 (21 April) \\
\hline 1977 (28 March) & 1973 (3 April) & 1992 (22 April) \\
\hline 1982 (26 March) & 1974 (3 April) & 1993 (26 April) \\
\hline 1985 (4 March) & 1979 (4 April) & 1995 (17 April) \\
\hline 1989 (28 March) & 1980 (3 April) & 1996 (18 April) \\
\hline 1991 (25 March) & 1981 (30 March) & 1997 (25 April) \\
\hline 1999 (9 March) & 1984 (4 April) & 2004 (15 April) \\
\hline $2000(23 \mathrm{March})$ & 1986 (6 April) & 2005 (30 April) \\
\hline 2002 (28 March) & 1988 (1 April) & 2007 (19 April) \\
\hline 2008 (16 March) & 1994 (8 April) & 2013 (19 April) \\
\hline 2010 (27 March) & 1998 (5 April) & 2014 (16 April) \\
\hline \multirow[t]{6}{*}{2012 (27 February) } & 2001 (5 April) & 2016 (13 April) \\
\hline & 2003 (2 April) & 2017 (9 April) \\
\hline & 2006 (1 April) & \\
\hline & 2009 (4 April) & \\
\hline & 2011 (5 April) & \\
\hline & 2015 (2 April) & \\
\hline
\end{tabular}

sition, with $\mathrm{PC} 1$ decreasing below $-5 \sigma$ in mid-May for all transition groups. To test whether early transitions are more abrupt (and therefore more dynamically disruptive) than later transitions, we compared the composite evolution of PC1 with respect to each year's transition date and did not find any significant differences in the vigor of the transition (Fig. S3).

\subsection{Relationship between the spring transition and STT-PBL}

This section will show how the spring transition modulates STT-PBL over western North America. We find that earlier transitions enhance the amount of the time the jet occupies its transitional phase, corresponding to a more invigorated storm track, more folds, and therefore more STT-PBL than later transitions. Early in the season, deeper folds enhance STTPBL, while later in the season more expansive folds enhance STT-PBL.

STT-PBL is modulated by the phase of the jet and corresponding invigoration of the storm track (Fig. 4). Transport increases by roughly threefold when the jet is in its transition phase, compared to the composite STT-PBL during both the winter and summer phases. STT-PBL was averaged over western North America (box in Fig. 4b) for each day in the record and subsequently binned by PC1, confirming STT-
PBL is strongest when the jet is closer to its transitional phase than at either extremity (Figs. 5a, S4). Both the highest STTPBL days in the record and the highest median STT-PBL values occur during the transition phase, while the distributions during the winter and summer phases are indistinguishable from one another (Fig. 5a). Consistent with the STT-PBL changes, tropopause folds reach farthest into the troposphere during the transition phase, on average to $450 \mathrm{hPa}$, in contrast to median values near $400 \mathrm{hPa}$ during the winter phase and $300 \mathrm{hPa}$ during the summer phase (Fig. 5b). During the winter phase, shallow $(<300 \mathrm{hPa})$ and deep $(>400 \mathrm{hPa})$ folds are equally likely, reflecting high wintertime jet variability (Athanasiadis et al., 2010), while deep folds are more frequent than shallow folds during the transition phase. Shallow folds are overwhelmingly more likely during the summer phase, which might be related to the weaker jet and associated ageostrophic circulation during summer. Thus, while the STT-PBL distributions during the winter and summer phases are indistinguishable from one another, the fold depth distributions differ substantially.

In addition to changes in tropopause fold depth during the spring transition, the daytime PBL height in the interior west increases dramatically, meaning shallower folds can reach the top of the boundary layer. Consistent with the STT data, $6 \mathrm{~h}$ forecasts of PBL height valid at 18:00 UTC were aver- 
(a) $\mathrm{PC} 1>1 \sigma$

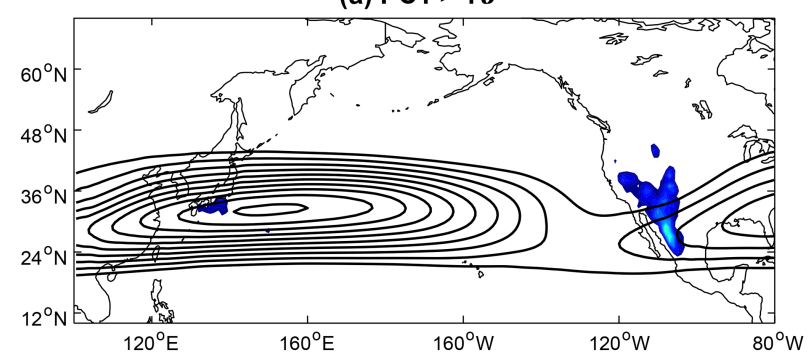

(b) PC1 +/- .5 $\sigma$

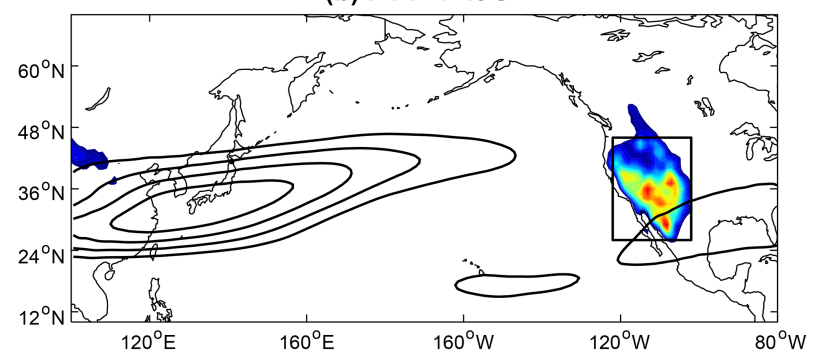

(c) PC1 $<-1 \sigma$

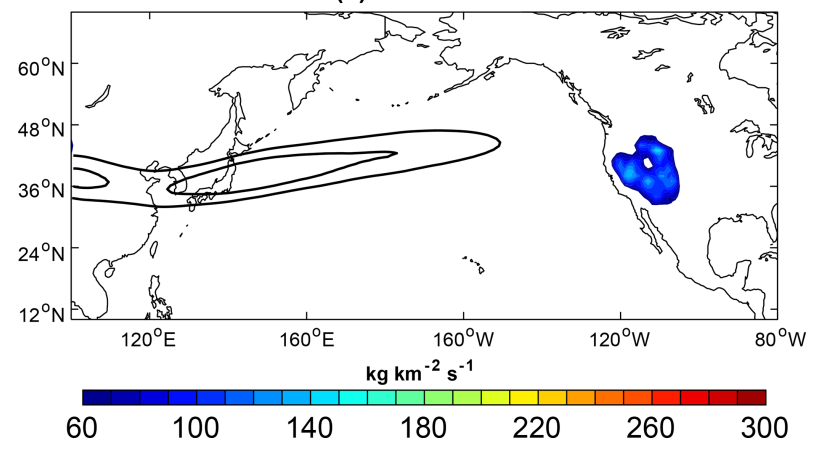

Figure 4. Composite STT-PBL during the three jet phases using ERA-Interim PC1 for 1980-2016. (a) STT-PBL during days characterized by a wintertime value $(N=998)$; (b) STT-PBL during days characterized by a transitional PC1 value $(N=952)$; (c) STT-PBL during days characterized by a summertime PC1 value $(N=1125)$. Zonal wind contours start at $30 \mathrm{~m} \mathrm{~s}^{-1}$ at intervals of $5 \mathrm{~m} \mathrm{~s}^{-1}$.

aged over western North America and grouped by jet phase (Fig. 5c), confirming the PBL deepens as the jet transitions. Thus, while folds deeper than $500 \mathrm{hPa}$ still occur somewhat frequently during the winter phase, the PBL is far lower, meaning a smaller subset of folds is deep enough to penetrate the boundary layer compared to the transition phase. Conversely, when the jet occupies the summer phase, despite a very deep boundary layer, there is limited transport due to a relative lack of intrusions deeper than $350 \mathrm{hPa}$. The transition phase is associated with higher STT-PBL through the coincidence of both more frequent deep tropopause folds and a deepening PBL. We note that STT-PBL can be displaced spatially from the position of the tropopause-level folds measured here and can be aided by lower-tropospheric vertical
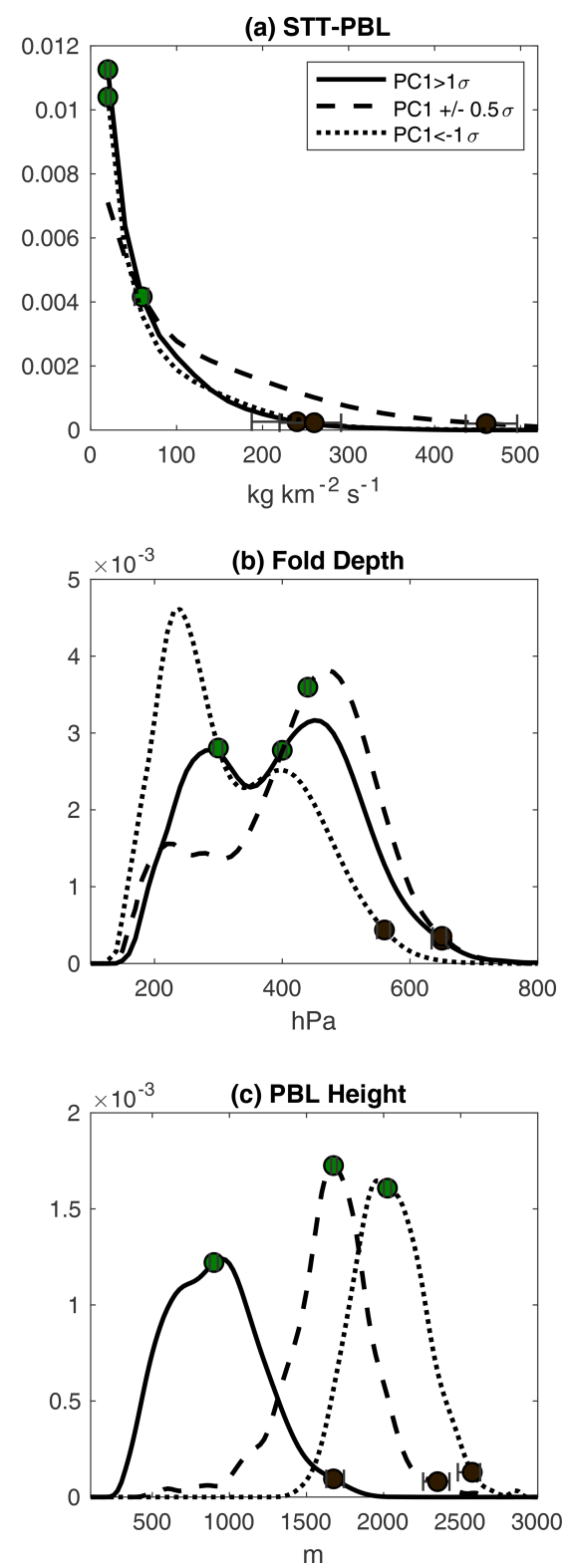

Figure 5. (a) Distribution of STT-PBL during positive (solid), neutral (dashed), and negative (dotted) jet phases. (b) As in (a) but for the distribution of the maximum tropopause fold pressure observed within folds passing over the western United States. (c) As in (a) but for $6 \mathrm{~h}$ forecasts of 18:00 UTC PBL height. The green dots show the bootstrapped medians of each distribution, and the black dots show the bootstrapped 99 th percentile values.

motions such as those occurring around frontal zones and convection (Škerlak et al., 2019, their Fig. 1).

Reconsidering the eddy characteristics associated with the three jet phases (Fig. 2), it appears that tropopause folds deep enough to produce STT-PBL occur most often when waves are highly amplified and the storm track is most energetic. Highly amplified Rossby waves are associated with strong curvature, particularly on the western edge of troughs, 

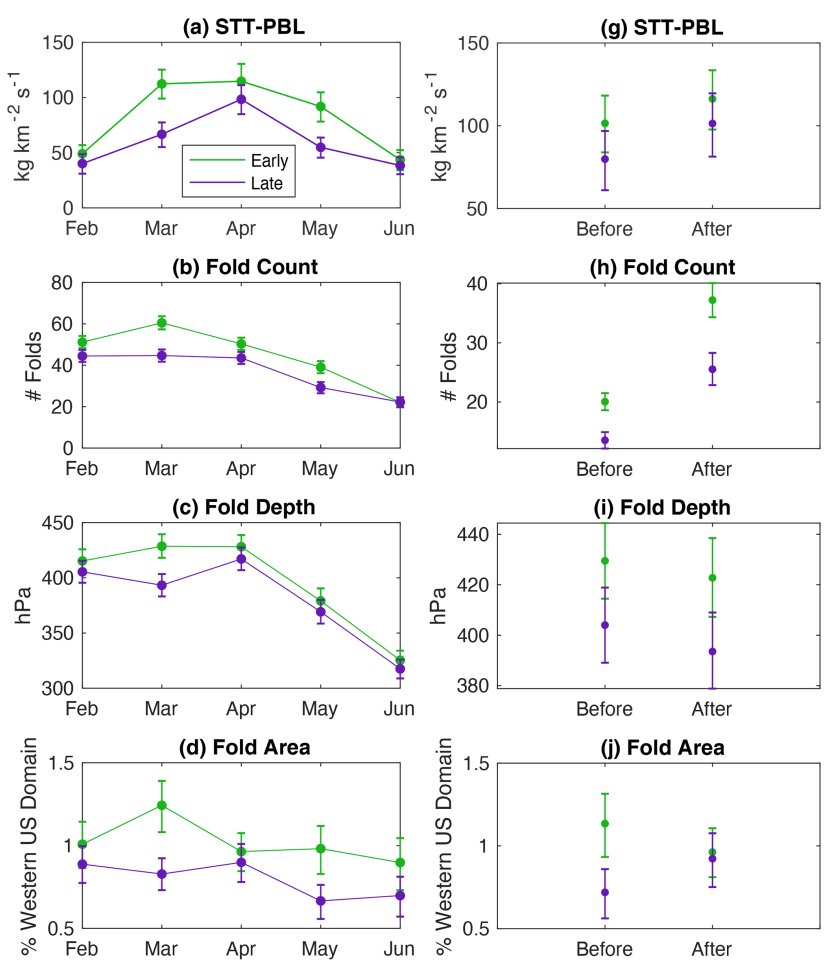

(e) Residence Time
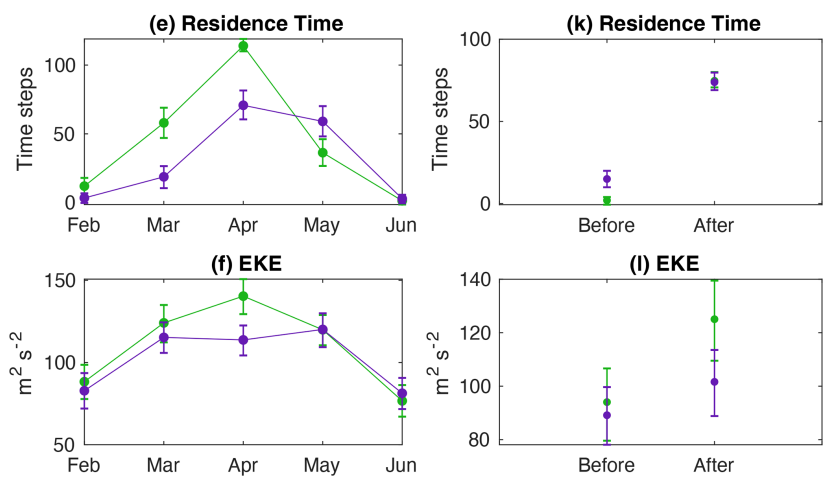

Figure 6. Bootstrapped (a) mean STT-PBL, (b) fold frequency, (c) fold depth, (d) fold size, (e) mean residence time of the jet, and (f) mean EKE for February-June during early transition years (green) and late transition years (purple). Panels (g-l) show the same variables averaged over the period 5 to $20 \mathrm{~d}$ prior to each year's transition date (days -20 to -5 ; Table 1), labeled "Before", and the 2 weeks following the transition date, days 0 to +14 , labeled "After".

producing the subsidence that forms deep tropopause folds and STT-PBL (e.g., Sprenger et al., 2007). Amplified waves propagating over western North America, which occur most often during the transition phase, bring more folds over the high terrain of the Rocky Mountains as the PBL deepens, leading to the STT-PBL maximum observed in boreal spring.

Given the longer period of time the jet is within its transition phase (when $\mathrm{PC} 1 \pm 0.5 \sigma$ ), hereafter referred to as the residence time, (Fig. 3), we hypothesize that early transition years are characterized by more STT-PBL than late transition
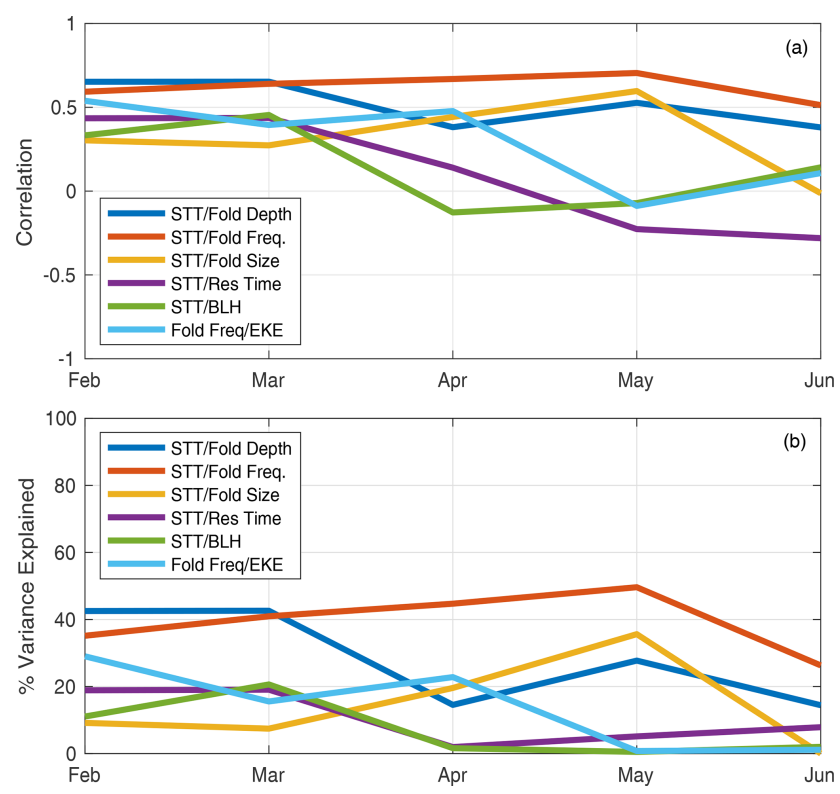

Figure 7. (a) Time series of the correlation $(r)$ of monthly mean STT-PBL with various tropopause fold characteristics, residence time of PC1 \pm 5 , mean PBL height, and mean EKE. Panel (b) shows the corresponding percent variance $\left(r^{2}\right)$ explained by each relationship.

years. To that end, we compared monthly mean STT-PBL for the early and late transition groups, revealing there is indeed more STT-PBL during early transition years in March, April and May, coinciding with more frequent folds deeper than $400 \mathrm{hPa}$ (Fig. 6a-b). In February and March, folds are deeper and larger in early transition years as well, while in later months folds are larger but not deeper (Fig. 6c-d). The residence time of the jet is much greater during early years by definition, and monthly mean EKE over the North Pacific $\left(180-250^{\circ} \mathrm{E}, 40-60^{\circ} \mathrm{N}\right.$; box in Fig. S6) is greater in April during early years (Fig. 6e-f). Compositing each variable with respect to each year's transition date reveals an upward shift in STT-PBL in the 2 weeks following the transition in both groups, coincident with a marked increase in tropopause folds, residence time, and EKE (Fig. 6g, h, k, l). Fold depth and area, conversely, are not systematically affected by the transition (Fig. 6i, j).

The relationship between STT-PBL and each related but distinct fold characteristic - maximum depth, fold area, and frequency - evolves over the course of the spring transition. This is evident from time series of the correlation between monthly mean STT-PBL, February-June, with each fold characteristic, residence time of the jet, and median PBL height (Fig. 7; Fig. S4). During February and March, STTPBL has the strongest correlation with fold depth and frequency, consistent with intuition. In April, however, the relationship between STT-PBL and fold depth diminishes, while fold frequency maintains a strong relationship with transport through June. In contrast to fold depth, the relationship be- 

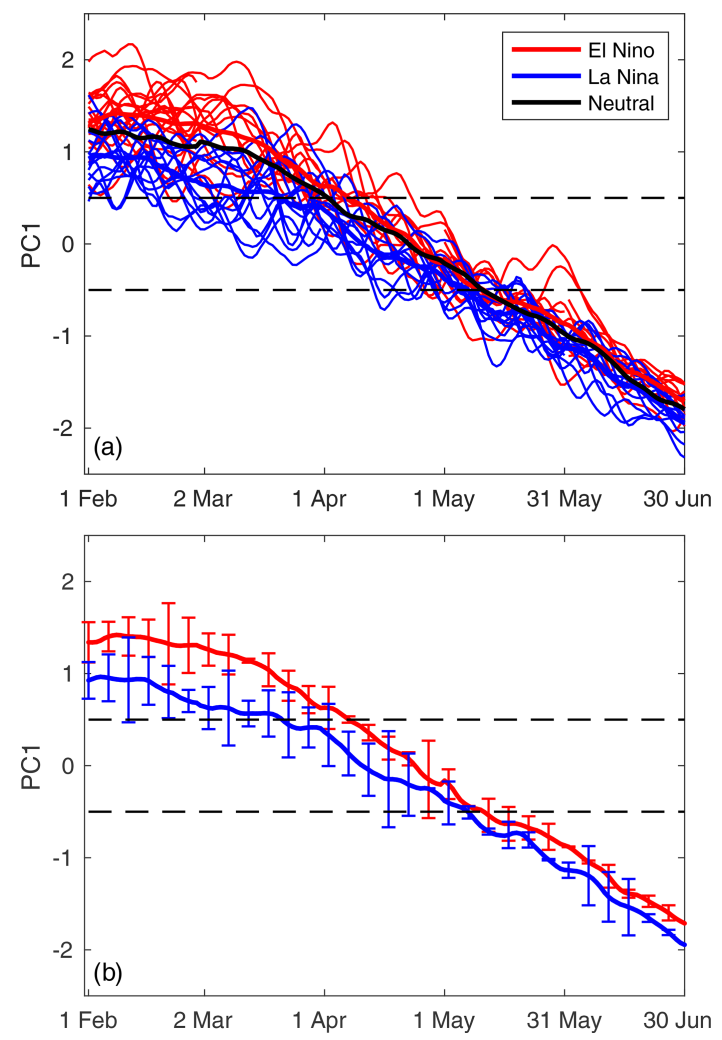

Figure 8. (a) The thin lines show PC1 values (using JRA-55) during months of La Niña events (blue) and El Niño events (red), with the thick blue (red) line showing the average La Niña (El Niño) periods. The thick black line shows the PC1 average for the remaining neutral months. Panel (b) shows the bootstrapped confidence intervals for the mean PC1 values for La Niña events (blue) and El Niño events (red).

tween fold size and STT-PBL is strongest in May, when it has the second-strongest relationship after frequency. A longer residence time of the jet within the transition phase enhances STT-PBL in March and February, a relationship which disappears later in spring, in part because PC1 continues decreasing towards its summertime state. Daytime PBL height and STT-PBL are modestly correlated in February and March, with no relationship in later months when the daytime PBL has deepened to several kilometers and appears to no longer be the limiting factor for deep transport (Fig. 5c; Seidel et al., 2012; Langford et al., 2017). Since fold frequency maintains a strong relationship with STT-PBL throughout the transition, we correlated fold frequency to EKE, confirming that a more energetic storm track is associated with more folds and supporting the relationship between storm track variability, folds, and STT-PBL. The correlation drops off by May, however, for reasons which are not immediately clear but might reflect the more convective nature of transport during this time of year, which can be important for transport to the surface (Langford et al., 2017; Škerlak et al., 2019). Overall, fold frequency maintains the strongest relationship with STT-
PBL throughout the transition, while fold depth and area also affect STT-PBL early and late in the transition, respectively.

\subsection{Impact of ENSO on the spring transition and STT-PBL}

What drives the substantial variability in the timing of the spring transition (Fig. 3)? While prior research has alluded to a connection between ENSO and STT-PBL, the precise nature of the ENSO-fold-STT relationship during boreal spring is not fully understood. Here we demonstrate that ENSO conditions do influence the jet, tropopause fold characteristics, and STT-PBL and that this influence evolves throughout the spring transition.

ENSO markedly affects the jet from February-April, with La Niña conditions corresponding to a much lower PC1 value than neutral or El Niño conditions, while in May and June the differences are weaker (Fig. 8). There is some asymmetry in the PC1 response, with La Niña weakening the jet more substantially than El Niño strengthens it. Given the positive relationship between STT-PBL and residence time of the jet, we hypothesize that La Niña conditions are associated with enhanced STT-PBL, which is broadly confirmed in Figs. 910 and is consistent with the conclusions of Lin et al. (2015). In February and March, El Niño conditions are associated with a zonally extended jet that connects to the jet over North America, while the jet is zonally confined to the central $\mathrm{Pa}$ cific during La Niña (Fig. 9a-f). STT-PBL is overall weak in February but is strongest during La Niña years, consistent with the most neutral PC1 value. STT-PBL increases in all three ENSO groups during March, as PC1 values decrease. Note that the jet has already transitioned during many of the La Niña and some of the ENSO-neutral years (Table 1). In April, the jet transition is either underway or has already occurred, and correspondingly STT-PBL peaks for the El Niño and ENSO-neutral groups and remains elevated for La Niña (Figs. 9g-i, 10a). During May and June, STT-PBL remains elevated during La Niña years, although the difference compared to ENSO-neutral is somewhat uncertain with the number of samples available (Figs. 9j-o, 10a). The (presumably eddy-driven) jet core in the western Pacific is stronger during La Niña years, reflecting an increase in storm track activity compared to neutral and El Niño conditions coincident with a more negative PC1 value (Figs. 10f, S6).

Which of the various tropopause fold characteristics explored in the prior section do ENSO conditions affect? Just as the influence of ENSO on PC1 evolves over the course of the transition, so too does the influence of ENSO on tropopause folds. During February and March, La Niña conditions are characterized by significantly deeper and more frequent folds, driving an increase in STT-PBL (Fig. 10ac). Folds are also larger, particularly in May when the relationship between fold area and STT-PBL is the strongest (Fig. 10d). While STT-PBL during April is similar in all three groups, folds are still more frequent and potentially 
(a) February El Nino

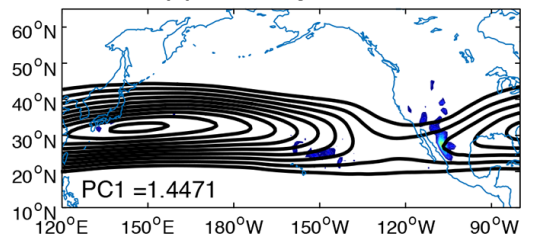

(d) March El Nino

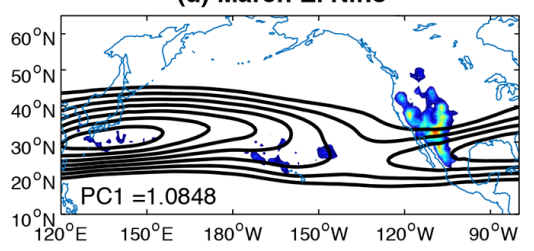

(g) April El Nino

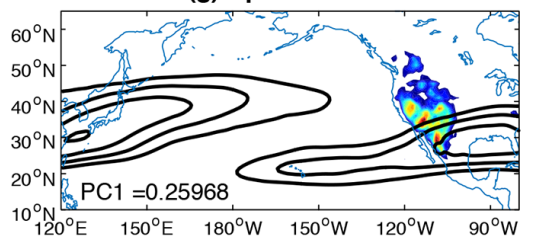

(j) May EI Nino

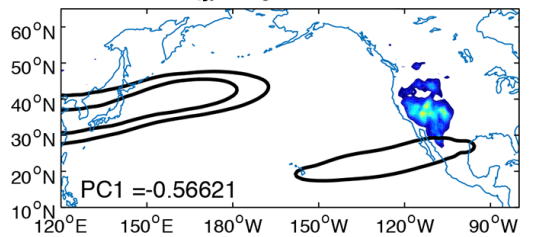

(m) June El Nino

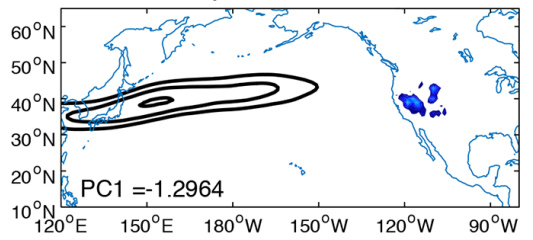

(b) February Neutral

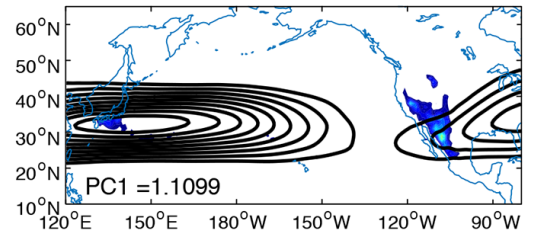

(e) March Neutral

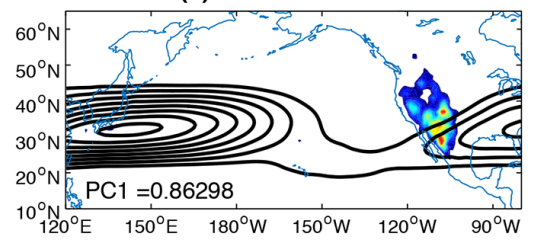

(h) April Neutral

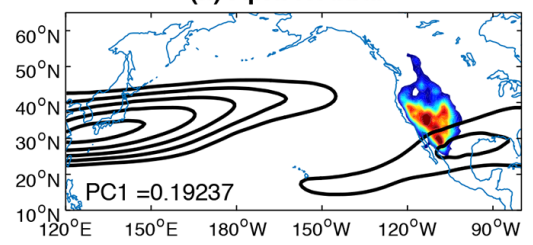

(k) May Neutral

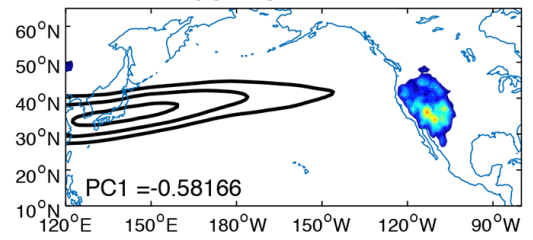

(n) June Neutral

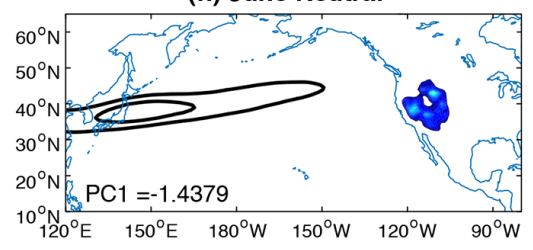

(c) February La Nina

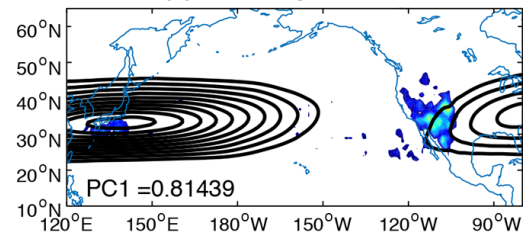

(f) March La Nina

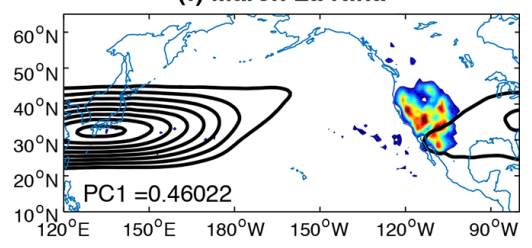

(i) April La Nina

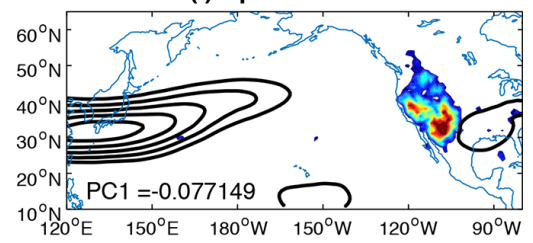

(I) May La Nina

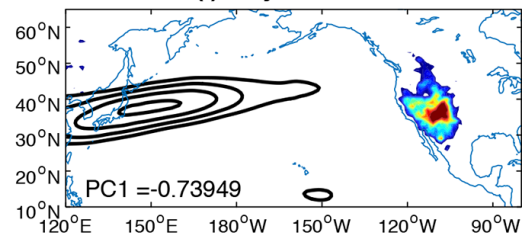

(o) June La Nina

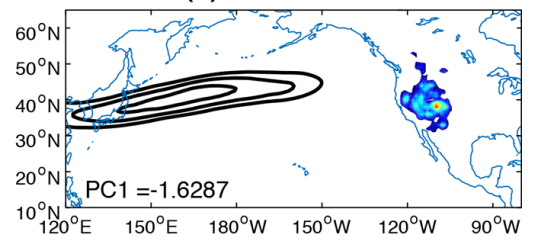

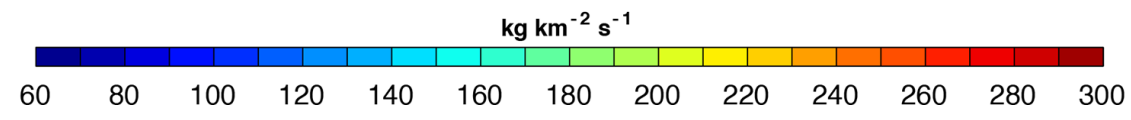

Figure 9. The color shading shows the monthly mean STT-PBL during El Niño conditions (left), ENSO-neutral conditions (middle), and La Niña conditions (right). The black contours show the monthly mean $200 \mathrm{hPa}$ zonal wind. The mean PC1 values for each month and ENSO group are shown in the bottom left corner. Zonal wind contours start at $30 \mathrm{~m} \mathrm{~s}^{-1}$ at intervals of $5 \mathrm{~m} \mathrm{~s}^{-1}$.

deeper during La Niña (Fig. 10b-c). STT-PBL is elevated during La Niña in May, when folds are more common and larger in areal extent. Mean fold depth, in contrast to fold size, is insensitive to ENSO phase in May and June. Finally, the residence time of the jet within its transition phase is significantly enhanced in February and March (as suggested in Fig. 8), while it is reduced in May when PC1 is more negative (Figs. 10e, 91). EKE during La Niña is most enhanced in April, similar to the early transition years (Figs. 10f, 6f), due to the notable increase in EKE following the transition (Fig. 101, 61). The $\boldsymbol{E}$-vector differences indicate more amplified and positively tilted waves during La Niña, reflecting the enhanced anticyclonic Rossby wave breaking occurring during this phase (Fig. S6). Note that during May, EKE is enhanced during La Niña in a smaller region over the eastern Pacific (Fig. S6d), accompanied by a more zonal $\boldsymbol{E}$ vector, consistent with elevated STT-PBL observed in Fig. 10a but not reflected in Fig. 10f. 

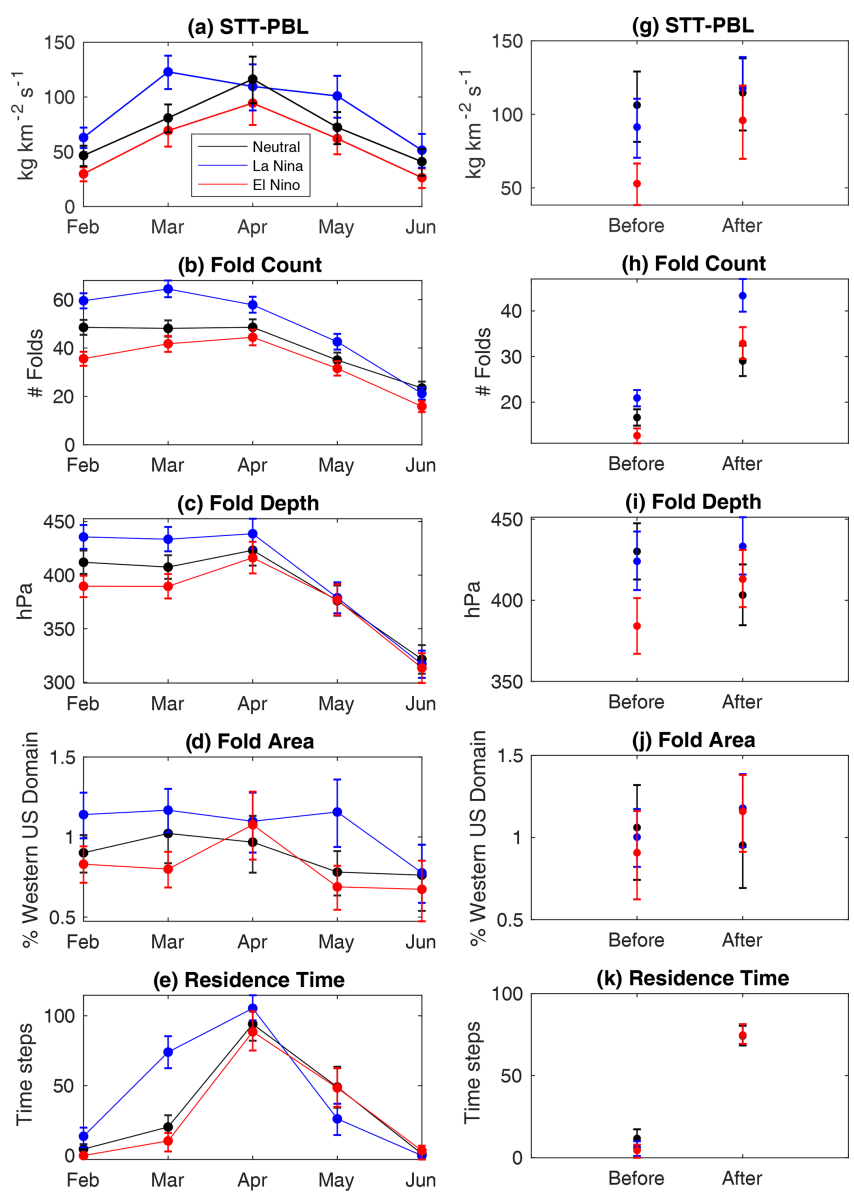

(f) EKE
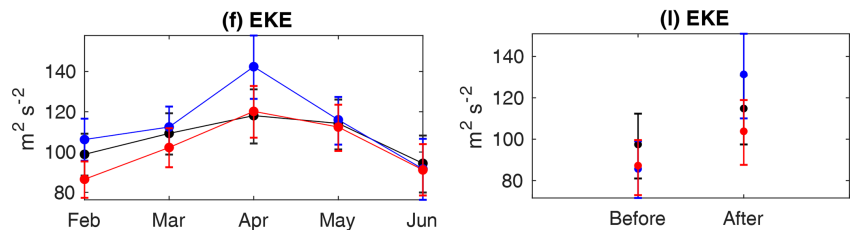

Figure 10. As in Fig. 6 but grouped by El Niño years (red), La Niña years (blue), and ENSO-neutral years (black).

In summary, in late winter or early spring, the teleconnection to the extratropics during La Niña projects onto the seasonal transition of the jet represented by PC1, often expediting the transition. This large-scale modulation, in turn, enhances the depth of tropopause folds and fold frequency over western North America, enhancing STT-PBL. In May, La Niña conditions continue to increase the frequency and size of folds and therefore STT-PBL, also through invigoration of the storm track as in February and March (Fig. S6). An opposite response is observed during El Niño conditions.

\section{Discussion and conclusions}

The present study seeks to further clarify the relationship between the North Pacific jet, tropopause folds, and deep mass transport and how these connections evolve from FebruaryJune over the western United States using JRA-55 and ERAInterim reanalysis. The leading EOF and corresponding PC of $200 \mathrm{hPa}$ zonal wind are demonstrated to track the winterto-summer jet evolution. The nature of this transition is consistent with previous studies of the annual cycle of the jet (Newman and Sardeshmukh, 1998) and the associated changes in the storm track (Nakamura, 1992; Hoskins and Hodges, 2019). We find that the spring jet transition modulates folds and STT-PBL and that the timing of the transition varies from mid-March to late April. In February and March, early transitions lead to enhanced STT-PBL through an increase in the depth and frequency of tropopause folds over western North America. Conversely, late transitions are characterized by shallower, less frequent folds and weaker STTPBL. Early transitions preferentially occur during La Niña conditions, while there is a weaker but still notable link between El Niño conditions and late transitions. In February and March, La Niña conditions enhance STT-PBL through an increase in fold depth and frequency, while in May, STTPBL is greater through an increase in fold size and frequency.

The peak in STT-PBL during boreal spring over western North America found by previous studies occurs through the simultaneous occurrence of the dynamic North Pacific jet transition and seasonal deepening of the PBL. The highly amplified flow observed during the spring transition increases the frequency of deep stratospheric intrusions, as the PBL deepens due to enhanced solar heating, strengthening STT-PBL. The association between more STT-PBL and highly amplified flow found here is consistent with case studies of notable stratospheric-ozone intrusion events over the western US (Langford et al., 2009; Lin et al., 2015; Knowland et al., 2017) and the established role of Rossby wave breaking in facilitating STT (Homeyer and Bowman, 2013). The zonal wind anomalies associated with the transitional phase also resemble the April-May zonal wind anomalies found during years with the greatest mixing ratios of ozone observed in stratospheric intrusions (Albers et al., 2018). The present analysis offers a simple metric to track such jet variability and situates it within the context of the seasonal transition.

Our results are consistent with the differences in STTPBL of ozone observed between ENSO phase during AprilMay over western North America by Lin et al. (2015). This is notable because we only consider mass transport without measuring how the ozone concentrations within folds vary between ENSO, which can be quite substantial (GarcíaHerrera 2006; Neu et al., 2014; Albers et al., 2018). The influence of ENSO on the ozone reservoir opposes the effect of ENSO on folds - namely, La Niña (El Niño) conditions reduce (enhance) extratropical lower stratospheric-ozone concentrations, by modification of the Brewer-Dobson Circulation (Neu et al., 2014; Albers et al., 2018). As such, from our results which focus on tropopause fold changes, but not stratospheric-ozone changes associated with ENSO, it is dif- 
ficult to draw conclusions about deep ozone transport and ENSO from this study, while deep mass transport is clearly modified. Finally, we note that STT-PBL does not necessarily guarantee the transport of ozone or mass all the way to the surface, which can be strongly influenced by PBL dynamics and ageostrophic circulations around low-level frontal zones (Škerlak et al., 2019).

This study took advantage of recently developed products specifically targeted at understanding STT-PBL using ERA-Interim reanalysis fields (Sprenger et al., 2007, 2017; Dee et al., 2011; Škerlak et al., 2014). We note that, as a consequence, our results concerning STT-PBL are limited to the ERA-Interim record and the frequency of ENSO events within the 1980-2016 period (excluding Sect. 3.1 and Fig. 8, which used the 60-year JRA-55 reanalysis record). To minimize the possibility of overstating subsequent conclusions regarding folds and STT-PBL, we have applied rather strict significance testing to account for sampling and autocorrelation, confirming that the differences we have highlighted are frequently statistically significant. Future work could employ model simulations using many ensembles to increase the sample size of early or late transition years and ENSO events to revisit the connections found in this study. Finally, different flavors of ENSO events (i.e., east- and central-Pacific El Niño events) and their influence on the jet and STT-PBL, could be explored in future work.

Code availability. The code used to perform this analysis can be accessed by personal communication with the corresponding author. The reanalysis products used in this study are available through the National Center for Atmospheric Research/University Consortium for Atmospheric Research Data Archive: https://rda.ucar.edu/ (Research Data Archive at the National Center for Atmospheric Research, 2019). The tropopause fold metrics and STT-PBL variable are available at monthly resolution from http://eraiclim.ethz.ch/ (ETH Zürich, 2019).

Supplement. The supplement related to this article is available online at: https://doi.org/10.5194/acp-21-2781-2021-supplement.

Author contributions. MLB wrote the code, produced the figures, and wrote the paper. AHB and JRA provided computational resources and frequent guidance during the study and provided edits and comments to the paper. MS provided the STT-PBL and tropopause fold datasets and provided edits and comments to the paper. AOL provided edits and comments to the paper.

Competing interests. The authors declare that they have no conflict of interest.
Acknowledgements. The authors would like to thank Matthew Newman for constructive conversations regarding the spring transition, which in part motivated this study. Melissa L. Breeden was supported by the NOAA Climate and Global Change Postdoctoral Fellowship Program, administered by UCAR's Cooperative Programs for the Advancement of Earth System Science (CPAESS) under award no. NA18NWS4620043B.

Financial support. This research has been supported by the NOAA Climate and Global Change Postdoctoral Fellowship Program (grant no. NA18NWS4620043B). JRA and AHB were funded in part by NSF grant no. 1756958 .

Review statement. This paper was edited by Ashu Dastoor and reviewed by two anonymous referees.

\section{References}

Albers, J. R., Perlwitz, J., Butler, A. H., Birner, T., Kiladis, G. N., Lawrence, Z. D., and Dias, J.: Mechanisms governing interannual variability of stratosphere-to-troposphere ozone transport, J. Geophys. Res.-Atmos., 123, 234-260, https://doi.org/10.1002/2017JD026890, 2018.

Athanasiadis, P. J., Wallace, J. M., and Wettstein, J. J.: Patterns of winter- time jet stream variability and their relation to the storm tracks, J. Atmos. Sci., 67, 1361-1381, https://doi.org/10.1175/2009JAS3270.1, 2010.

Breeden, M. L., Hoover, B. T., Newman, M., and Vimont D. J.: Optimal North Pacific Blocking Precursors and their Deterministic Subseasonal Evolution during Boreal Winter, Mon. Weather Rev., 148, 739-761, https://doi.org/10.1175/MWR-D-19-0273.1, 2020.

Breeden, M. L. and Martin J. E.: Analyzing the onset of an extreme North Pacific Jet Retraction using Piecewise Tendency Diagnosis, Q. J. R. Meteor. Soc., 144, 1895-1913, https://doi.org/10.1002/qj.3388, 2018.

Christenson, C. E., Martin, J. E., and Handlos Z. J.: A synopticclimatology of Northern Hemisphere, cold season polar and subtropical jet superposition events, J. Climate, 30, 7231-7246, 2017.

Danielsen, E. F.: Project Springfield Report, Tech. Rep. 1517, 110 pp., Defense At. Supp. Agency, Washington, D. C., 1964.

Danielsen, E. F.: Stratospheric-tropospheric exchange based on radioactivity, ozone and potential vorticity, J. Atmos. Sci., 25, 502518, 1968.

Dee, D. P., Uppala, S. M., Simmons, A. J., et al.: The ERAInterim reanalysis: Configuration and performance of the data assimilation system, Q. J. R. Meteorol. Soc., 137, 553-597, https://doi.org/10.1002/qj.828, 2011.

Eichelberger, S. J. and Hartmann, D. L.: Zonal jet structure and the leading mode of variability, J. Clim., 20, 5149-5163, 2007.

ETH Zürich: Feature-based ERA-Interim Climatologies: available at: http://eraiclim.ethz.ch/, last access: 10 January 2019.

Fleming, E. L., Lim, G.-H., and Wallace, J. M.: Differences between the spring and autumn circulation of the Northern Hemisphere, J. Atmos. Sci., 44, 1266-1286, 1987. 
García-Herrera, R., Calvo, N., Garcia, R., and Giorgetta, M.: Propagation of ENSO temperature signals into the middle atmosphere: A comparison of two general circulation models and ERA-40 reanalysis data, J. Geophys. Res., 111, D06101, https://doi.org/10.1029/2005JD006061, 2006.

Gettelman, A., Hoor, P., Pan, L., Randel, W., Hegglin, M., and Birner, T.: The extratropical upper troposphere and lower stratosphere, Rev. Geophys., 49, RG3003, https://doi.org/10.1029/2011RG000355, 2011.

Homeyer, C. R. and Bowman, K. P.: Rossby wave breaking and transport between the tropics and extratropics above the subtropical jet, J. Atmos. Sci., 70, 607-626, 2013.

Hoskins, B. J., James, I. N., and White G. H.: The Shape, Propagation and Mean-Flow Interaction of LargeScale Weather Systems, J. Atmos. Sci., 40, 15951612, $\quad$ https://doi.org/10.1175/1520-0469(1983)040< 1595:TSPAMF>2.0.CO;2, 1983 .

Hoskins, B. J., McIntyre, M. E., and Robertson, A. W.: On the use and significance of isentropic potential vorticity maps, Q. J. R. Meteorol. Soc., 111, 877-946, https://doi.org/10.1002/qj.49711147002, 1985.

Hoskins, B. J. and Ambrizzi T.: Rossby wave propagation on a realistic longitudinally varying flow, J. Atmos. Sci., 50, 1661-1671, https://doi.org/10.1175/15200469(1993)050,1661:RWPOAR.2.0.CO;2, 1993.

Hoskins, B. J. and Hodges, K. I.: The Annual Cycle of Northern Hemisphere Storm Tracks. Part II: Regional Detail, J. Climate, 32, 1761-1775, 2019.

Jaffe, S.C., Martin, J.E., Vimont, D.J., and Lorenz, D.J.: A synopticclimatology of episodic, sub-seasonal retractions of the Pacific jet, Journal of Climate, 24, 2846-2860, 2011.

Keyser, D. and Shapiro, M. A.: A review of the structure and dynamics of upper-level frontal zones, Mon. Weather Rev., 114, 452-499, https://doi.org/10.1175/15200493(1986)114<0452:AROTSA>2.0.CO;2, 1986.

Knowland, K. E., Ott, L. E., Duncan, B. N., and Wargan, K.: Stratospheric intrusion-influenced ozone air quality exceedances investigated in the NASA MERRA-2 reanalysis, Geophys. Res. Lett., 44, 10691-10701, https://doi.org/10.1002/2017GL074532, 2017.

Kobayashi, S., Ota, Y., Harada, Y., Ebita, A., Moriya, M., Onoda, H., et al.: The JRA-55 reanalysis: General specifications and basic characteristics. Journal of the Meteorological Society of Japan. Ser. II, 93, 5-48. https://doi.org/10.2151/jmsj.2015-001, 2015.

Langford, A., O’Leary, T., Masters, C., Aikin, K., and Proffitt, M.: Modulation of middle and upper tropospheric ozone at northern midlatitudes by the El Niño/Southern Oscillation, Geophys. Res. Lett., 25, 2667-2670, 1998.

Langford, A., Aikin, K., Eubank, C., and Williams, E.: Stratospheric contribution to high surface ozone in Colorado during springtime, Geophys. Res. Lett., 36, L12801, https://doi.org/10.1029/2009GL038367, 2009.

Langford, A., Brioude, J., Cooper, O., Senff, C., Alvarez, R., Hardesty, R., and Oltmans, S.: Stratospheric influence on surface ozone in the Los Angeles area during late spring and early summer of 2010, J. Geophys. Res., 117, D00V06, https://doi.org/10.1029/2011JD016766, 2012.
Langford, A. O., Alvarez II, R. J., Brioude, J., et al.: Entrainment of stratospheric air and Asian pollution by the convective boundary layer in the southwestern U.S., J. Geophys. Res.-Atmos., 122, 1312-1337, https://doi.org/10.1002/2016JD025987, 2017.

Lareau, N. P. and Horel, J. D.: The Climatology of SynopticScale Ascent over Western North America: A Perspective on Storm Tracks. Mon. Weather Rev., 140, 1761-1778, https://doi.org/10.1175/MWR-D-11-00203.1, 2012.

Lefohn, A. S., Wernli, H., Shadwick, D., Oltmans, S. J., and Shapiro, M.: Quantifying the importance of stratospheric-tropospheric transport on surface ozone concentrations at high- and low-elevation monitoring sites in the United States, Atmos. Environ., 62, 646-656, https://doi.org/10.1016/j.atmosenv.2012.09.004, 2012.

Li, C. and Wettstein, J. J.: Thermally Driven and Eddy-Driven Jet Variability in Reanalysis, J. Climate, 25, 1587-1596, https://doi.org/10.1175/JCLI-D-11-00145.1, 2012.

Lin, M. Y., Fiore, A. M., Cooper, O. R., Horowitz, L. W., Langford, A. O., Levy, H., Johnson, B. J., Naik, V., Oltmans, S. J., and Senff C. J.: Springtime high surface ozone events over the western United States: Quantifying the role of stratospheric intrusions, J. Geophys. Res., 117, D00v22, https://doi.org/10.1029/2012jd018151, 2012.

Lin, M., Horowitz, L. W., Oltmans, S. J., Fiore, A. M., and Fan S.: Tropospheric ozone trends at Mauna Loa Observatory tied to decadal climate variability, Nat. Geosci., 7, 136-143, https://doi.org/10.1038/ngeo2066, 2014.

Lin, M., Fiore, A. M., Horowitz, L. W., Langford, A. O., Oltmans, S. J., Tarasick, D., and Rieder, H. E.: Climate variability modulates western US ozone air quality in spring via deep stratospheric intrusions, Nat. Commun., 12, 7105, https://doi.org/10.1038/ncomms8105, 2015.

Martius, O., Schwierz, C., and Davies, H. C.: Breaking waves at the tropopause in the wintertime Northern Hemisphere: climatological analyses of the orientation and the theoretical LC1/2 classification, J. Atmos. Sci., 64, 2576-2592, 2007.

Nakamura, H.: Midwinter suppression of baroclinic wave activity in the Pacific, J. Atmos. Sci., 49, 1629-1642, 1992.

Neu, J. L., Flury, T., Manney, G. L., Santee, M. L., Livesey, N. J., and Worden, J.: Tropospheric ozone variations governed by changes in stratospheric circulation, Nat. Geosci., 7, 340-344, 2014.

Newman, M., and Sardeshmukh, P. D.: The impact of the annual cycle on the North Pacific/North American response to remote low-frequency forcing, J. Atmos. Sci., 55, 1336-1353, 1998.

NOAA Center for Weather and Climate Prediction, NOAA Oceanic Niño Index: Cold \& Warm Episodes by Season, available at: https://origin.cpc.ncep.noaa.gov/products/analysis_ monitoring/ensostuff/ONI_v5.php, last access: 8 June 2020.

Pan, L. L., Randel, W. J., Gille, J. C., Hall, W. D., Nardi, B., Massie, S., Yudin, V., Khosravi, R., Konopka, P., and Tarasick, D.: Tropospheric intrusions associated with the secondary tropopause, J. Geophys. Res., 114, D10302, https://doi.org/10.1029/2008JD011374, 2009.

Peters, D. and Waugh, D. W.: Rossby wave breaking in the Southern Hemisphere wintertime upper troposphere, Mon. Weather Rev., 131, 2623-2634, 2003.

Reed, R. J. and Danielsen E. F.: Fronts in the vicinity of the tropopause, Arch. Meteor. Geophy. A, 11, 1-17, 1959. 
Renwick, J. A. and Wallace, J. M.: Relationships between North Pacific wintertime blocking, El NinPo, and the PNA pattern. Mon. Weather Rev., 124, 2017-2076, https://doi.org/10.1175/15200493(1996)124,2071:RBNPWB.2.0.co;2, 1996.

Research Data Archive at the National Center for Atmospheric Research: Computational and Information Systems Laboratory, available at: https://rda.ucar.edu/, last access: 11 January 2019.

Rivière, G. and Joly A.: Role of the Low-Frequency Deformation Field on the Explosive Growth of Extratropical Cyclones at the Jet Exit. Part II: Baroclinic Critical Region, J. Atmos. Sci., 63, 1982-1995, https://doi.org/10.1175/JAS3729.1, 2006.

Schemm, S. and Sprenger, M.: The Life Cycle of Upper-Level Troughs and Ridges: A Novel Detection Method, Climatologies and Lagrangian Characteristics, Weather Clim. Dynam., 1, 459479, https://doi.org/10.5194/wcd-1-459-2020, 2020.

Seidel, D. J., Zhang, Y., Beljaars, A., Golaz, J.-C., Jacobson, A. R., and Medeiros, B.: Climatology of the planetary boundary layer over the continental United States and Europe, J. Geophys. Res., 117, D17106, https://doi.org/10.1029/2012JD018143, 2012.

Shapiro, M.: Turbulent mixing within tropopause folds as a mechanism for the exchange of chemical constituents between the stratosphere and troposphere, J. Atmos. Sci., 37, 994-1004, 1980.

Shapiro, M., Wernli, H., Bond, N., and Langland, R.: The influence of the 1997-99 El Niño Southern Oscillation on extratropical baroclinic life cycles over the eastern North Pacific, Q. J. R. Meteorol. Soc., 127., 331-342, 2001.

Škerlak, B., Sprenger, M., and Wernli, H.: A global climatology of stratosphere-troposphere exchange using the ERA-Interim data set from 1979 to 2011, Atmos. Chem. Phys., 14, 913-937, https://doi.org/10.5194/acp-14-913-2014, 2014.

Škerlak, B., Sprenger, M., Pfahl, S., Tyrlis, E., and Wernli H.: Tropopause folds in ERA-Interim: Global climatology and relation to extreme weather events, J. Geophys. Res.-Atmos., 120, 4860-4877, https://doi.org/10.1002/2014JD022787, 2015.
Škerlak, B., Pfahl, S., Sprenger, M., and Wernli, H.: A numerical process study on the rapid transport of stratospheric air down to the surface over western North America and the Tibetan Plateau, Atmos. Chem. Phys., 19, 6535-6549, https://doi.org/10.5194/acp-19-6535-2019, 2019.

Sprenger, M. and Wernli, H.: A northern hemispheric climatology of cross-tropopause exchange for the ERA15 time period (1979-1993), J. Geophys. Res., 108, 8521, https://doi.org/10.1029/2002JD002636, 2003.

Sprenger, M., Wernli, H., and Bourqui, M.: StratosphereTroposphere Exchange and Its Relation to Potential Vorticity Streamers and Cutoffs near the Extratropical Tropopause, J. Atmos. Sci., 64, 1587-1602, https://doi.org/10.1175/JAS3911.1, 2007.

Sprenger, M., Fragkoulidis, G., Binder, H., Croci-Maspoli, M., Graf, P., Grams, C. M., Knippertz, P., Madonna, E., Schemm, S., Škerlak, B., and Wernli H.: Global climatologies of Eulerian and Lagrangian flow features based on ERAInterim reanalyses, B. Am. Meteorol. Soc., 98, 1739-1748 https://doi.org/10.1175/BAMS-D-15-00299.1, 2017.

Staley, D. O.: On the mechanism of mass and radioactivity transport from stratosphere to troposphere, J. Atmos. Sci., 19, 450-467, 1962.

Voulgarakis, A., Hadjinicolaou, P., and Pyle, J.: Increases in global tropospheric ozone following an El Nino event: Examining stratospheric ozone variability as a potential driver, Atmos. Sci. Lett., 12, 228-232, 2011.

Wernli, H. and Davies, H. C.: A Lagrangian-based analysis of extratropical cyclones. I: The method and some applications, Q. J. R.. Meteor. Soc., 123, 467-489, 1997.

Zeng, G. and Pyle, J. A.: Influence of El Niño Southern Oscillation on stratosphere/troposphere exchange and the global tropospheric ozone budget. Geophys. Res. Lett., 32, L01814, https://doi.org/10.1029/2004GL021353, 2005. 